\title{
Persistent carotid-vertebrobasilar anastomoses: cases of proatlantal artery Type I and Type II
}

\author{
Özhan Özgür ${ }^{1}$, Güneş Aytaç ${ }^{2}$, Muzaffer Sindel $^{3}$, Timur Sindel ${ }^{1}$ \\ ${ }^{1}$ Department of Radiology, School of Medicine, Akdeniz University, Antalya, Turkey \\ ${ }^{2}$ Department of Anatomy, School of Medicine, Yiiksek İhtisas University, Ankara, Turkey \\ ${ }^{3}$ Department of Anatomy, School of Medicine, Akdeniz University, Antalya, Turkey
}

\begin{abstract}
Persistence of fetal communications between the carotid and vertebrobasilar systems is uncommon. Persistent proatlantal artery is an anastomosis between the carotid and vertebrobasilar systems, typically classified as Type I and II. In this case report, 600 angiographies are examined retrospectively and two persistent proatlantal arteries were observed - one with Type I ( $0.16 \%)$ and the other with Type II (0.16\%) proatlantal artery. Existence of these arteries are associated with intracranial vascular anomalies, especially aneurysms. In both of our cases, an aneurysm was detected in the middle cerebral artery. Precise knowledge of these anastomoses is essential for intracranial operations and catheterizations performed in this region.
\end{abstract}

Keywords: angiography; carotid-vertebrobasilar anastomosis; persistent proatlantal artery

Anatomy 2018;12(2):101-104 @2018 Turkish Society of Anatomy and Clinical Anatomy (TSACA)

\section{Introduction}

Persistent carotid-vertebrobasilar anastomoses occur as a result of discontinuation in the development of the vertebrobasilar system. ${ }^{[1]}$ These are embryonic presegmental arteries supplying the primitive vertebrobasilar system from the primitive internal carotid artery (ICA) ${ }^{[1-4]}$ The primitive vertebrobasilar system comprises two parallel longitudinal neural arteries supplied by the carotid system with four major anastomoses. ${ }^{[5]}$ In the early stage of embryonic life, these longitudinal neural arteries supply the hindbrain. Blood flows here by the embryonic cerebral arteries that directly connect the carotid and basilar arteries. These arteries form anastomoses named presegmental arteries and are named by the adjacent cranial nerves: ${ }^{[1]}$ trigeminal, otic, hypoglossal, and proatlantal. Presegmental arteries provide connection between the longitudinal neural arteries and the internal carotid artery, and disappear after the development of the posterior communicating and vertebral arteries. The one that persists most frequently is the primitive trigeminal artery with an incidence of $0.2 \%$ in cerebral angiograms. The incidence of other presegmental arteries were found as $0.1 \%$ after birth. ${ }^{[6]}$ Persistant proat- lantal artery (PPA) is classified Type I and Type II. Both types are rare developmental anomalies; both originate from the carotid artery and enter the cranium through the foramen magnum.

Type I originates from the ICA, takes a dorsal course cephalad to the transverse process of $\mathrm{C} 1$, and then travels rostral to enter the foramen magnum. Type II proatlantal artery arises from the external carotid artery (ECA) laterally, remains more lateral in position than the Type I artery, and joins the course of the horizontal portion of the vertebral artery (VA) before entering the foramen magnum $^{[1,7]}$ (Figure 1). Type I does not pass through the transverse foraminae of the cervical vertebrae; in contrast, Type II passes through the transverse foramen of $\mathrm{C} 1$ vertebra and then joins with the V3 of the VA. ${ }^{[1]}$ We studied cerebral angiographies performed between 2011-2015 at The Department of Radiology, School of Medicine, Akadeniz University, Antalya, Turkey to reveal subarachnoidal haemorrhagies retrospectively and investigate carotid-vertebrobasilar anastomoses. Out of 600 angiographies examined retrospectively, only two cases with persistent proatlantal artery were observed. 


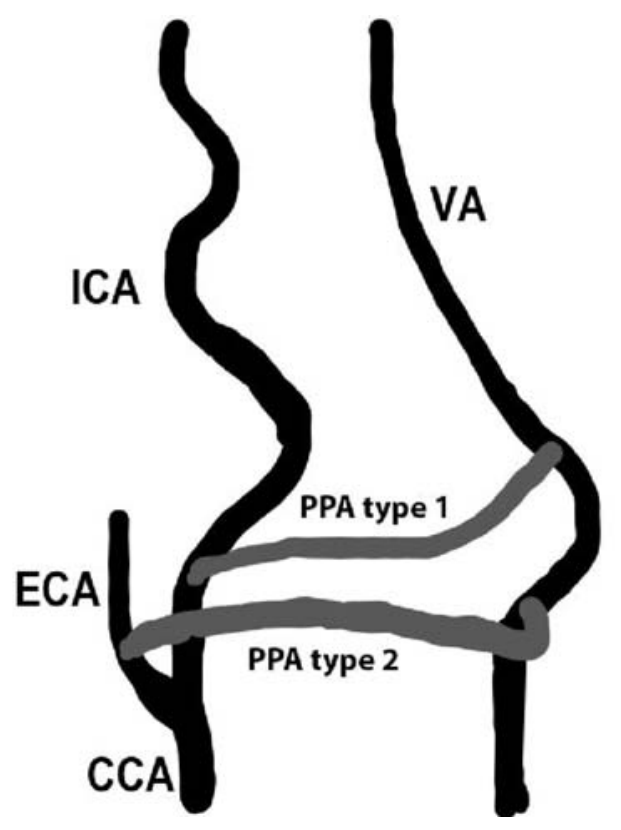

Figure 1. Illustration of proatlantal arteries; Type I and Type II. CCA: common carotid artery; ECA: external carotid artery; ICA: internal carotid artery; PPA: persistant proatlantal artery; VA: vertebral artery.

\section{Case Report}

Case 1

In the first case, angiography of the right common carotid artery (CCA) indicated that the CCA continued with the middle cerebral artery (MCA). At the bifurcation level of the MCA a saccular aneurysm was detected (Figure 2a). Angiography of the left CCA showed that Type I proatlantal artery originated from the cervical part of the ICA. The left VA arose through the Type I proatlantal artery and ICA continued with the left anterior cerebral artery (ACA) and MCA, and the right ACA was visualized via the anterior communicating artery (Figure 2b). The left VA was filled by the proatlantal artery and continued with the basilar artery. Two posterior cerebral arteries were also visualized (Figures 2c and $\mathbf{d}$ ). In the angiography of the left subclavian artery, proximal part of VA was not visualized (Figure 2e).

\section{Case 2}

In this case, angiography of the right CCA showed that the right MCA and ACA were arising from ICA and left
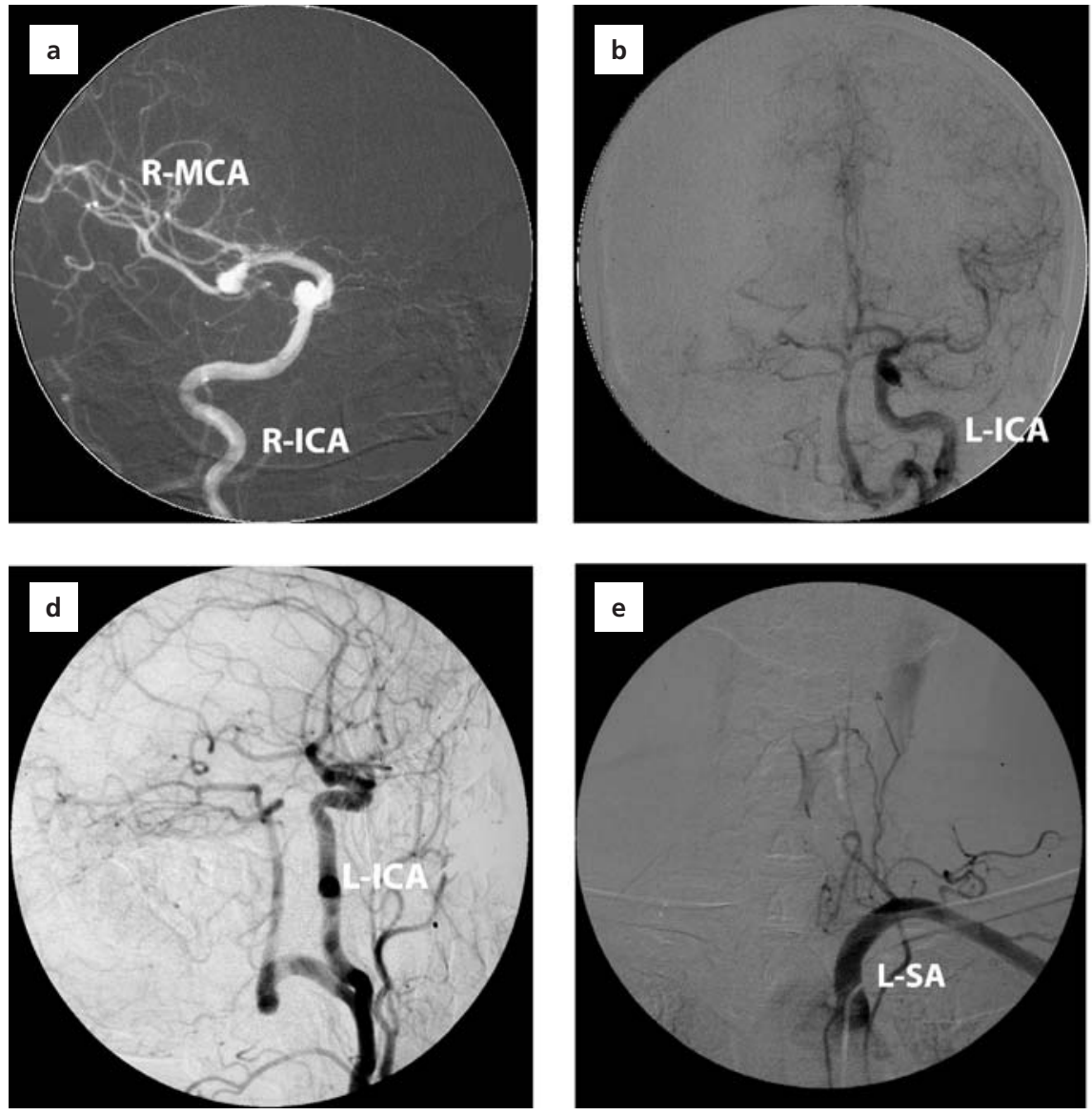

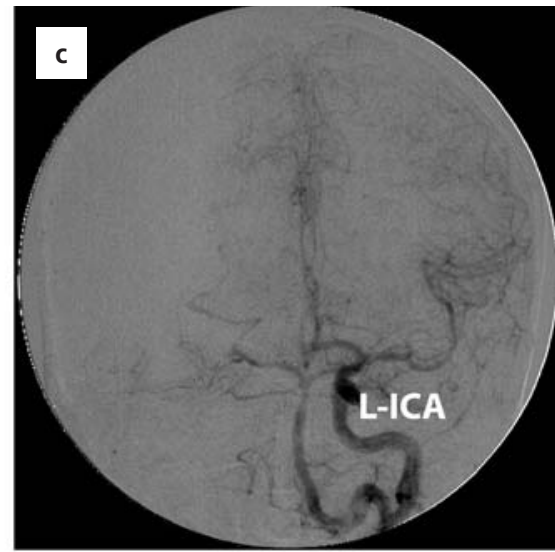

Figure 2. (a) A saccular aneurysm in R-MCA. $V A$ arises through the Type I proatlantal artery, ICA was continued with the left ACA and MCA. (b) Right ACA is visualized via the anterior communicating artery. (c, d) The left VA is filled by proatlantal artery and continued with the basilar artery. (e) Proximal part of left VA is absent in the angiography of the left subclavian artery. L-ICA: left internal carotid artery; L-SA: left subclavian artery; L-VA: left vertebral artery; R-ICA: right internal carotid artery; R-MCA: right middle cerebral artery; VA: vertebral artery. 
ACA was visualized via the anterior communicating artery (Figures 3a and b). Angiography of the left CCA showed that the ICA is continued isolated MCA. From the ECA, a thick Type II persistent proatlantal artery arose and VA was filled through this artery (Figure 3c and d). Right VA originated from the right subclavian artery as usual, but on the left side, proximal part of VA wasn't visualized (Figure 3e).

\section{Discussion}

Persistence of fetal communications between the carotid and vertebrobasilar systems is uncommon. We found the PPA artery incidence as $0.33 \%$ in our study. Bilateral or unilateral presence of PPA Type I was described in some earlier studies. ${ }^{[7-11]} \mathrm{We}$ found the incidence of Type I PPA as $0.16 \%$ in this study. Bilateral or unilateral presence of PPA Type II was also described previously. ${ }^{[4,12,13]}$ We found Type II PPA in $0.16 \%$ of the angiographies. Woodcock et al. ${ }^{[10]}$ found proatlantal artery Type I in 57\%, Type II in $38 \%$, and arising from the common carotid artery in $5 \%$. As in our case, most of the proatlantal arteries were found incidentally. Purkayastha et al. ${ }^{[9]}$ suggested that the actual incidence of PPA is probably higher than reported, because in most cases, the discovery is purely coincidental. Existence of these arteries are associated with intracranial vascular anomalies, especially aneurysms. ${ }^{[10,14,15]}$ Y Ylmaz et al. ${ }^{[1]}$ reported clinical and pathological findings in combination with these primitive persistent anastomoses in seven cases. Tubbs et al. ${ }^{[14]}$ mentioned that, for the co-existence of PPA and aneurysms is reported in the literature, no consensus has been reached as to whether this is an association or simply incidental. In both of our cases, an aneurysm was detected in the MCA. This finding promotes the idea that PPA might be associated with vascular anomalies; however, more extensive studies are needed to clarify this.

Persistence of the proatlantal artery into adult life can be explained on an embryological basis as of a primary error in the development of the VA. ${ }^{[12]}$ Therefore, PPA can be accompanied by ipsilateral, contralateral or bilateral aberrant VAs. ${ }^{[7]}$ Coincidence of PPA and hypoplasia of the ipsilateral, contralateral or both VA was reported as $46 \% .{ }^{[16]}$ In both of our cases, proximal parts of the ipsilateral VA was absent. Bahşi et al. ${ }^{[17]}$ conferred that when the VA is absent, posterior cerebral circulation is supplied by persistent arteries, and occlusion of these arter-

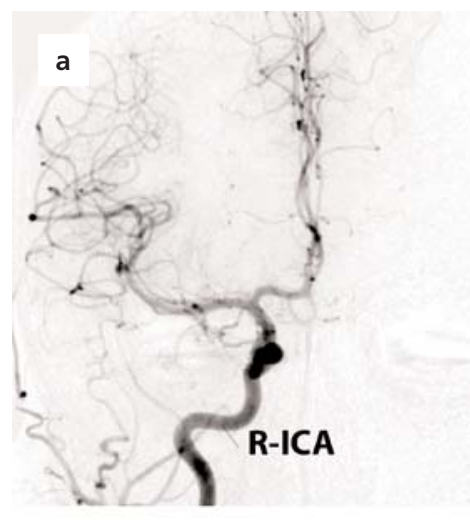

Figure 3. (a-b) Right MCA and ACA arising from the ICA and left ACA is visualized via the anterior communicating artery; (c) Type II proatlantal artery; (d) Type II proatlantal artery; (e) Proximal part of left VA is absent in the angiography of the left subclavian artery. *Type II proatlantal artery; **Type II proatlantal artery; L-ECA: left external artery; R-ICA: right internal carotid artery; L-SA: left subclavian artery; L-VA: left vertebral artery; VA: vertebral artery.
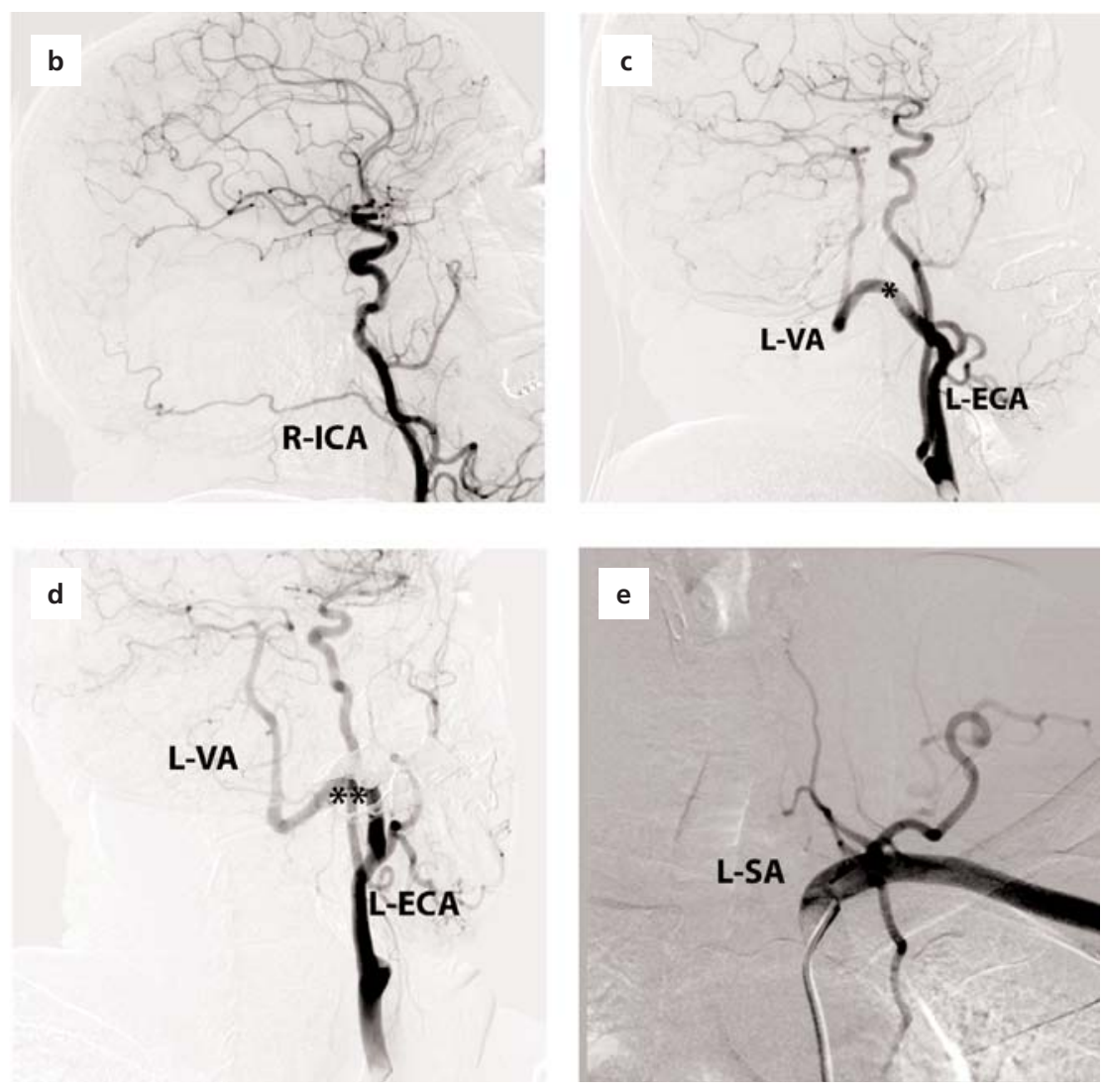
ies results in ischemia of the area. ${ }^{[17]}$ Therefore, the knowledge of these persistent arteries before surgery can be crucial while designing the surgical procedure. ${ }^{[9,16,17]}$

The coincidence of PPA and aneurysms is mentioned in many studies including our study. ${ }^{[7,10,14,15]}$ Besides this, some authors suspected that PPA might be associated with other symptoms or clinical findings such as tinnitus, ischemic cerebrovascular diseases, arteriovenous malformations. ${ }^{[12,13,18]}$ Kolbinger et al. ${ }^{[18]}$ described a case with right cerebellar infarction and ischemic lesions in the left dorsal thalamus and the right upper parietal lobe. In this case, the angiography showed occlusion of the right ICA proximal to an ipsilateral proatlantal artery Type I. They suggested their case demonstrated the clinical significance of a persistent proatlantal artery in the evolution of an atypical ischemic cerebrovascular disease.

\section{Conclusion}

The literature on the PPA and other persistent primitive arteries are mostly case reports and/or literature reviews. Thus, incidence of this artery is undecided. Although coincidence of PPA and vascular anomalies is mentioned in numerous articles, there is no consensus about this issue. Also, association with PPA and other diseases or symptoms is still not clear. When the clinical importance of this artery is considered, extended and retrospective studies like this are necessary.

\section{References}

1. Vasović L, Mojsilović M, Andelković Z, Jovanović I, Arsić S, Vlajković S, Milenković Z. Proatlantal intersegmental artery: a review of normal and pathological features. Childs Nerv Syst 2009; 25:411-21.

2. Caldemeyer KS, Carrico JB, Mathews VP. The radiology and embryology of anomalous arteries of the head and neck. AJR Am J Roentgenol 1998;170:197-203.

3. Vasović L, Arsić S, Vlajković S, Jovanović I, Jovanović P, Ugrenović S, Andjelković Z. Otic artery: a review of normal and pathological features. Med Sci Monit 2010;16:Ra101-9.

4. Vasović L, Milenković Z, Jovanović I, Cukuranović R, Jovanović P, Stefanović I. Hypoglossal artery: a review of normal and pathological features. Neurosurg Rev 2008;31:385-95.
5. Ranchod AI, Gora G, Swartz RN, Andronikou S, Mngomezulu V. A rare carotid-basilar anastomosis traversing the jugular foramen: origin and clinical implications. Interv Neuroradiol 2011;17:347-50.

6. Bergman RA, Afifi AK, Miyauchi R. Persistent embryologic arteries (hyaloid, hypoglossal, stapedial, and trigeminal). Illustrated encyclopedia of human anatomic variation: opus ii: cardiovascular system: listing of the cardiovascular system.https://www.anatomyatlases.org/ AnatomicVariants/Cardiovascular/Directory/Region/ArteriesPersist ant.shtml [Retrieved April 1, 2018].

7. Tian Y, Wang YF, Du HG, Xu J, Zhang JM, Guo SX. Left type I proatlantal artery with bilateral aberrant vertebral arteries and a ruptured aneurysm: a case report and review of the literature. Surg Radiol Anat, 2015;37:689-92.

8. Gumus T, Onal B, Ilgit ET. Bilateral persistence of type 1 proatlantal arteries: report of a case and review of the literature. AJNR Am J Neuroradiol 2004;25:1622-4.

9. Purkayastha S, Gupta AK, Varma R, Kapilamoorthy TR. Proatlantal intersegmental arteries of external carotid artery origin associated with Galen's vein malformation. AJNR Am J Neuroradiol 2005;26: 2378-83.

10. Woodcock RJ, Cloft HJ, Dion JE. Bilateral type 1 proatlantal arteries with absence of vertebral arteries. AJNR Am J Neuroradiol 2001; 22:418-20.

11. Yilmaz E, Ilgit E, Taner D. Primitive persistent carotid-basilar and carotid-vertebral anastomoses: a report of seven cases and a review of the literature. Clin Anat 1995;8:36-43.

12. Arraez-Aybar LA, Navia-Alvarez P, Mendez-Cendon JC. A case of a type II proatlantal artery with arteriovenous malformation. Surg Radiol Anat 2011; 33:85-9.

13. Li TH, Lan MY, Liu JS, Tseng YL, Wu HS, Chang YY. Type II proatlantal intersegmental artery associated with objective pulsatile tinnitus. Neurology 2008;71:295-6.

14. Tubbs RS, Verma K, Riech S, Mortazavi MM, Shoja MM, Loukas M, Curé JK, Zurada A, Cohen-Gadol AA. Persistent fetal intracranial arteries: a comprehensive review of anatomical and clinical significance. J Neurosurg 2011;114:1127-34.

15. Zarghouni M, Marichal D. Persistent bilateral proatlantal type II artery. Proc (Bayl Univ Med Cent) 2013;26:50-1.

16. Montechiari M, Iadanza A, Falini A, Politi LS. Monolateral type I proatlantal artery with bilateral absence of vertebral arteries: description of a case and review of the literature. Surg Radiol Anat 2013;35: $863-5$.

17. Bahşi YZ, Uysal H, Peker S, Yurdakul M. Persistent primitive proatlantal intersegmental artery (proatlantal artery I) results in 'top of the basilar' syndrome. Stroke 1993;24:2114-7.

18. Kolbinger R, Heindel W, Pawlik G, Erasmi-Körber H. Right proatlantal artery type I, right internal carotid occlusion, and left internal carotid stenosis: case report and review of the literature. J Neurol Sci 1993;117:232-9.

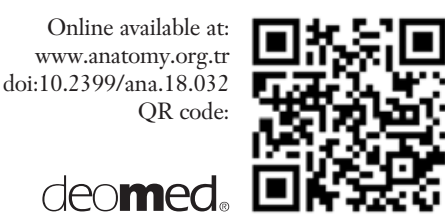

\author{
Correspondence to: Muzaffer Sindel, PhD \\ Department of Anatomy, School of Medicine, \\ Akdeniz University, Antalya, Turkey \\ Phone: +90 5322944762 \\ e-mail: sindelm@akdeniz.edu.tr
}

Conflict of interest statement: No conflicts declared.

This is an open access article distributed under the terms of the Creative Commons Attribution-NonCommercial-NoDerivs 3.0 Unported (CC BY-NCND3.0) Licence (http://creativecommons.org/licenses/by-nc-nd/3.0/) which permits unrestricted noncommercial use, distribution, and reproduction in any medium, provided the original work is properly cited. Please cite this article as: Özgür Ö, Aytaç G, Sindel M, Sindel T. Persistent carotid-vertebrobasilar anastomoses: cases of proatlantal artery Type I and Type II. Anatomy 2018;12(2):101-104. 